exclusive to a particular culture (and therefore bound to it) and has nothing to do with a gap between a 'scientifically aware medical population' and the 'myth orientated' natives (as Singh mentions). Unfortunately, the term continues to be used predominantly for psychiatric phenomena in non-Western cultures, which have been established and measured by using one cultural scale (mainly Western so far), to judge another. In fact, proponents of the 'new cross-cultural psychiatry' (Klienman, 1981; Littlewood, 1990), have argued that culture influences (Western) psychiatric theories no less than the myth-ridden ideas of natives that Singh refers to. This view may be 'new' to psychiatry but is certainly well established in the social sciences (Foucault, 1961; Gould, 1981).

If we wish to pursue a meaningful inquiry that clarifies the relationship between 'culture' and 'psychopathology', we need to get away from our own selfprofessed pre-Copernican views. It is certainly noble to convey the benefits of scientific knowledge to society, but that is no excuse for assumptions that breed methodological arrogance, value judgements (of 'true' and 'false' beliefs), and colonise society with views that are no less disorted than those of the 'natives'.

Gould, S. J. (1981) The Mismeasure of Man. Harmondsworth: Penguin.

Foucault, M. (1961) Folie et Deraison. Plon: Paris. (Translated by R. Howard 1972 as Madness and Civilization. Pantheon Books: New York.)

KLIENman, A. (1981) Patients and Healers in the Context of Culture. Berkeley: University of California Press.

Litrlewood, R. (1990) From categories to contexts: a decade of the 'new cross-cultural psychiatry'. British Journal of Psychiatry. 156, 308-327.

Department of Academic Psychiatry

SUSHRUT JADHAV

Middlesex Hospital

Mortimer Street

London WIN 8AA

SIR: I read Bhatia \& Malik's account of the Dhat syndrome (Journal, November 1991, 159, 691-695) with interest. The authors argue that the Dhat syndrome is a true culture-bound syndrome and describe the deeply ingrained cultural influences that underlie the syndrome in the Indian subcontinent. Singh (Journal, February 1992, 160, 280-281) makes the point that it is culture bound only in so far as it represents the immense difference between the scientifically aware medical and a myth-orientated native population.

In a surgical clinic in the United Arab Emirates (UAE) we saw many Indian and Pakistani expatriate workers who presented with lower urinary symptoms including frequency, dysuria, perineal discomfort, whitish urethral discharge, urinary turbidity, or simply loss of semen. Many complained of sexual difficulties and symptoms such as weakness and fatigue. Investigations, which often included an intravenous pyelogram, cystoscopy and prostatic massage, were usually normal. Our diagnoses included chronic prostatitis, prostatic congestion, nonspecific urethral syndrome, and 'functional' lower urinary symptoms.

Over $70 \%$ of the population of the UAE were expatriate workers, mainly from the Indian subcontinent. Most were single young men, employed as low-paid labourers. Housing and working conditions were poor and the culture was alien, but the greatest hardship was the absence of women in their lives. Our team, which included two Indian doctors, gradually became aware of the psychological origin of many of these symptoms. Unfortunately our approach was unchanged by this insight. Biomedical explanations were more familiar and it was difficult to break out of this mould. It was only after reading about the Dhat syndrome (Chadda, 1990) that I began to understand the experience and realise how misplaced our efforts were. Not all of these patients met the Dhat syndrome but they were all manifesting distress or disease through illness behaviour shaped by similar cultural influences.

Is the Dhat syndrome a true culture-bound syndrome? Before recognising a new disorder, Western medicine requires proof that it is a distinct entity and not a mere variant of other disorders. As yet, it is debatable if such proof exists for the Dhat syndrome. However, the cultural influences that give rise to the Dhat syndrome do significantly modify the clinical picture of psychiatric and physical disorders. This occurs in the Indian subcontinent, among its immigrants, and perhaps their descendants, born abroad. In such situations, when sociocultural factors profoundly influence the clinical picture, Tseng (1981) urges that we should modify our classification. Psychiatry (Littlewood, 1990) is the speciality most likely to recognise that proof is not always practicable and that less rigorous criteria are occasionally necessary before we recognise new conditions, or modify existing diagnostic categories. Unless psychiatry is the first to acknowledge the Dhat syndrome it is unlikely to be accepted by the medical profession as a whole. These cases will remain unrecognised and continue to be misdiagnosed in immigrants throughout the world, including the United Kingdom.

Chadda, R. K. \& Ahuja, N. (1990) Dhat syndrome. A sex neurosis in the Indian subcontinent. British Journal of Psychiatry. 156, $577-579$.

LitrLEWOOD, R. (1990) From categories to contexts: a decade of the 'new cross-cultural psychiatry'. British Journal of Psychiatry, 156, 308-327. 
Tseng, R. \& MCDermott, J. F. (1981) Culture, Mind and Therapy: An Introduction to Cultural Psychiatry. New York: Brunner/Mazel.

Research Office

JuSTIN HaY

Mapperley Hospital

Porchester Road

Nottingham NG36AA

\section{Idiopathic genital pain and fluvoxamine}

SIR: Idiopathic genital pain in men (prostotadynia) is a puzzling and refractory condition. It has not so far been the subject of rigorous psychiatric assessment and treatment. We attempted to determine which psychological factors were related to a good outcome in a prospective drug-treatment study. Fluvoxamine was chosen because of evidence that reduced levels of central 5-HT could cause chronic pain syndrome (Messing \& Lytle, 1977).

In a urology clinic, 50 consecutive patients with idiopathic genital pain were given a psychiatric interview, including pain and psychosexual history, supplemented by the Hospital Anxiety and Depression scale (HAD) (Zigmond \& Snaith, 1983) and analogue pain scores. Pain was typically reported as being mainly testicular $(42 \%)$ or perineal $(30 \%)$ but radiation to other perigenital sites was common. It was described as aching $(46 \%)$ or burning $(20 \%)$ with a mean duration of 5.6 years (range 3 months to 40 years).

Post-ejaculatory exacerbation was reported by $42 \%$, and $90 \%$ gained no benefit from analgesics. Aetiological factors included genital surgery $(26 \%)$, infection $(18 \%)$, and trauma $(19 \%)$. The complaints included dyspareunia (26\%), premature ejaculation $(16 \%)$ and erectile impotence $(10 \%)$. The following DSM-III-R diagnoses were made: major depressive episode in $26 \%$, anxiety disorder in $14 \%$, conversion disorder in $12 \%$, and none in $48 \%$.

In view of the high incidence of depression and poor response to analgesics, an open trial of fluvoxamine was performed in 24 patients. Of these, 12 suffered from affective disorder (major depression 8 , anxiety disorder 4) and 12 had no psychiatric disorder. The group with major depression and anxiety after eight weeks showed statistically significant reductions in mean pain scores on an analogue scale (depression mean pain score falling from 5.8 to 2.1, and anxiety from 7.5 to 1.0 ). In the affective disorder group, both anxiety and depression improved, both on patient report and on the HAD scale. Interestingly, the group with no psychiatric diagnosis did equally well with the mean pain score falling from 6.2 to 2.8 after eight weeks and with no change in anxiety or depression scores (HAD scale). It cannot therefore be claimed that it is simply the treatment of the affective disorder which is giving rise to the analgesic effect in these patients. Patients with sexual dysfunction and voiding disturbances reported concomitant improvement in these symptoms as pain resolved. It would appear that fluvoxamine may have a role in treating this chronic pain syndrome and associated symptoms whether or not there is coexisting affective disorder.

The likely mechanism here is of an increase in pain threshold and inhibition of nociception due to increased spinal 5-HT turnover. 5-HT neurons project from the nucleus raphe magnus to the dorsal horn of the spinal cord. Experimental stimulation of these neurons has been shown to increase the nociceptive threshold and induce analgesia (Fields, 1984). We await further clinical studies to determine whether 5-HT reuptake inhibitors are of value in other chronic pain syndromes.

FIELDS, H. L. (1984) Brainstem mechanisms of pain modulation. Advances in Pain Research and Therapy, 6, 241-252.

Messing, R. B. \& LYTLE, L. D. (1977) Serotonin containing neurones: their possible role in pain and analgesia. Pain, 4, 1-22. Zigmond, A. S. \& SNaith, R. P. (1983) The Hospital Anxiety and Depression Scale. Acta Psychiatric Scandinavia. 67, 361-370.

Department of Psychiatry

DOUGLAS TURKINGTON

St Nicholas Hospital

Newcastle Upon Tyne

Department of Psychiatry

Northern General Hospital Sheffield

Department of Urology

JoHN GRANT

Northern General Hospital

Sheffield

\section{'The current literature' - Worcester Development Project}

SIR: Although within the Worcester Development Project there has always been a feeling that we got on with the job while others wrote learned dissertations about how it should be done, it must be admitted that published work is somewhat scanty. I was indeed grateful to the Editor for his efforts which ultimately resulted in the book describing the project, published under the Royal College of Psychiatrists' imprint in 1991 (The Closure of Mental Hospitals, edited by Peter Hall \& Ian F. Brockington).

There have, nevertheless, been a few other publications over the years, for example, an early account by the Unit Manager and myself (Hall \& Gillard, 1982), and other valuable articles by nonpsychiatrists. These have, for example, included Christine Bennett's (1989) paper; the article by Dr Chris Dowrick et al (1980); and by the Worcester 